\title{
Mixed adenoneuroendocrine carcinoma of the ampulla of Vater: A case report
}

\author{
NICOLE MAX ${ }^{1}$, ALEXANDER ROTHE ${ }^{2}$ and CORD LANGNER ${ }^{1}$ \\ ${ }^{1}$ Institute of Pathology, Medical University, A-8036 Graz; ${ }^{2}$ Department of Surgery, General Hospital, A-4020 Linz, Austria
}

Received December 9, 2015; Accepted February 25, 2016

DOI: $10.3892 /$ mco.2016.858

\begin{abstract}
Mixed adenoneuroendocrine carcinomas (MANECs) are rare biphasic tumour types, which are morphologically recognisable as both gland-forming and neuroendocrine neoplasms. Within the gastrointestinal tract, MANECs occur predominantly in the stomach or colorectum. The present study described a case of a MANEC originating from the ampullary region. The patient presented with widespread metastatic disease. Biopsy samples obtained from the ampullary primary tumour disclosed a complex lesion with adenocarcinoma and neuroendocrine small cell carcinoma components, positive for the intestinal transcription factor caudal type homeobox-2 and for neuroendocrine markers, including chromogranin A, synaptophysin, cluster of differentiation 56/neural cell adhesion molecule. By contrast, biopsy samples obtained from metastatic tissue revealed pure neuroendocrine carcinoma. As exemplified by this true mixed tumour, tumour heterogeneity evolves as the major challenge in oncology today, with potentially severe implications for the choice of chemotherapy. The assessment of metastatic sites may render valuable diagnostic information that is crucial for clinical decision-making and patient management.
\end{abstract}

\section{Introduction}

Ampullary carcinomas represent $0.5 \%$ of all gastrointestinal malignancies. They are more common in men compared with in women, and are normally diagnosed in patients between 60 and 80-years old (1).

The vast majority of lesions reveal a glandular growth pattern. Among these, two predominant subtypes of adenocarcinoma have been identified, which show either pancreaticobiliary $(15-20 \%)$ or intestinal differentiation

Correspondence to: Dr Cord Langner, Institute of Pathology, Medical University, 25 Auenbruggerplatz, A-8036 Graz, Austria E-mail: cord.langner@medunigraz.at

Key words: mixed adenoneuroendocrine carcinoma, adenocarcinoma, neuroendocrine carcinoma, mixed tumour, tumour heterogeneity, metastasis, histology, immunohistochemistry, oncology, chemotherapy
(50-80\%) (2,3). Subclassification is clinically relevant, since in addition to advanced tumour stage and poor differentiation, the pancreaticobiliary subtype has been identified as an adverse prognostic factor $(2,4-6)$. Tumours with neuroendocrine differentiation, including neuroendocrine tumours and neuroendocrine carcinomas (NECs) are only rarely observed at this site $(4,7,8)$.

Mixed adenoneuroendocrine carcinomas (MANECs) are rare biphasic tumour types, which have only anecdotally been reported in the ampullary region (7,9-12). The current report described a patient with ampullary MANEC, presenting with widespread metastatic dissemination. Both primary and metastatic tissues are assessed by histology, which has not been previously well-described.

\section{Case report}

Clinical presentation. A 66-year-old female presented with painless jaundice for 2 days, unspecific abdominal pain and weight loss of $5 \mathrm{~kg}$ within the last three months, and was admitted to the Department of Surgery, General Hospital (Linz, Austria). Laboratory analysis revealed pathological liver function tests, with predominant cholestatic profile, including hyperbilirubinemia.

Upon endoscopy, an irregular tumour mass was detected in the ampullary region, measuring $\sim 4 \mathrm{~cm}$ in the largest diameter (Fig. 1). Whole-body 18F-fluorodeoxyglucose positron emission tomography was performed, which revealed multiple metastases to liver, spine, retroperitoneal lymph nodes and lungs (Fig. 2).

Histopathological analysis. Biopsy material of the ampullary lesion disclosed a complex malignant epithelial lesion with a non-invasive adenoma component progressing into invasive intestinal-type adenocarcinoma. Other parts of the lesion consisted of typical neuroendocrine small cell carcinoma with diffuse growth pattern, composed of small to medium sized cells with minimal cytoplasm and fusiform nuclei with finely granular chromatin and inconspicuous nucleoli (Fig. 3). The mitotic rate was high and necrosis occurred frequently. Upon immunohistochemical staining, the tumour was positive for neuroendocrine markers, including chromogranin A, synaptophysin and cluster of differentiation (CD)56/neural cell adhesion molecule (NCAM). The intestinal transcription factor, caudal type homeobox (CDX)-2, was positive for both 
A

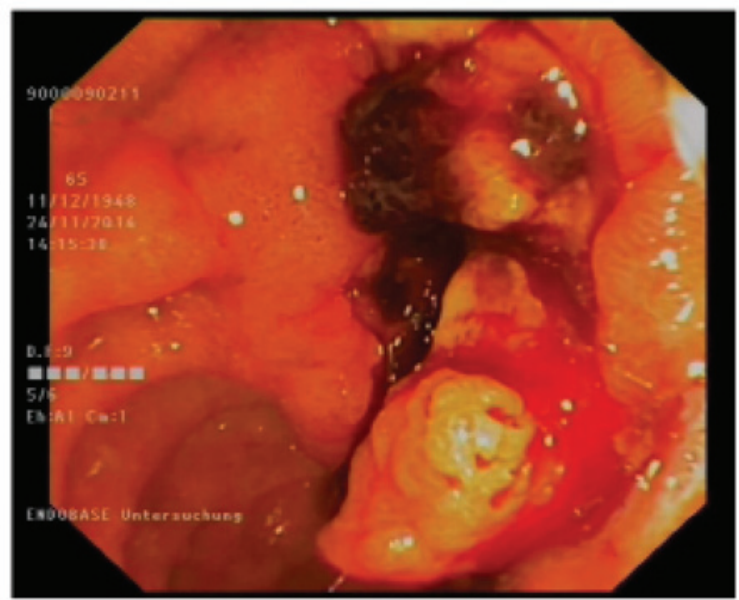

B

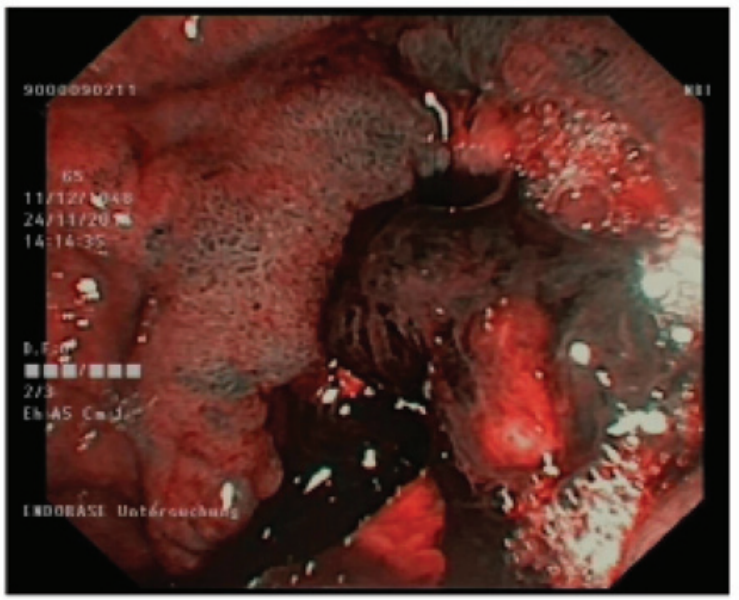

Figure 1. Large irregular polypoid tumour mass in the peri-ampullary region The tumor was observed by (A) white light endoscopy and (B) narrow band imaging.

exocrine and endocrine tumour components (Fig. 3). Based upon these findings, a diagnosis of MANEC of the ampulla was made.

Histology obtained from a liver lesion revealed pure neuroendocrine small cell cancer, which was positive for neuroendocrine markers and for CDX-2, thereby proving its gastrointestinal/ampullary origin (Fig. 4).

\section{Discussion}

The first description of a gastrointestinal tumour exhibiting both exocrine and neuroendocrine differentiation was published in 1924 by Cordier (13). The widespread use of immunohistochemical techniques in the last decades has led to the recognition that neuroendocrine cells are present rather frequently in exocrine malignancies of the gastrointestinal tract (14). True mixed tumour types, including MANECs, are relatively uncommon, occurring predominantly in the stomach and colorectum.

According to the World Health Organisation definition, MANECs are morphologically recognisable as both gland-forming and neuroendocrine neoplasms with an arbitrary requirement of at least $30 \%$ of either component (15). They are defined as carcinomas since both components are histologically malignant. MANECs must be differentiated

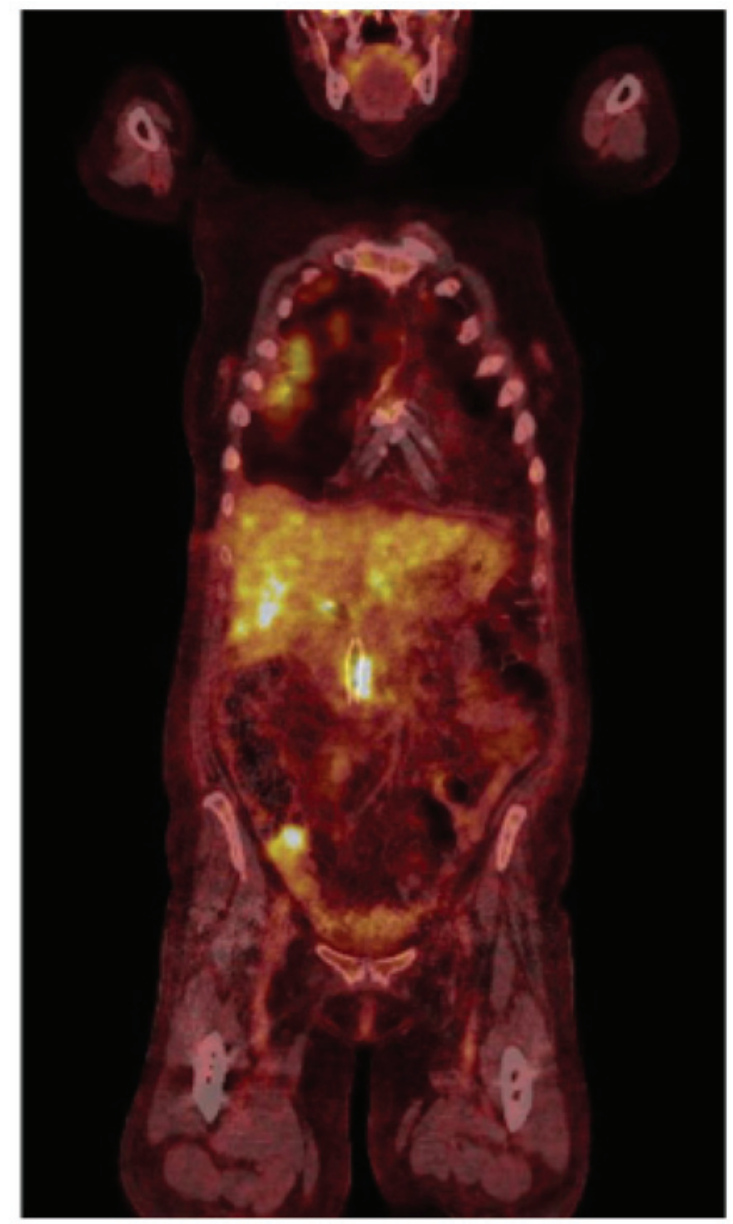

Figure 2. Whole-body $18 \mathrm{~F}$-fluorodeoxyglucose positron emission tomography. Multiple metastases (yellow/white) were observed in the liver, spine, retroperitoneal lymph nodes and lungs.

from collision tumour types (16) or so-called amphicrine tumour types (17), which are characterized by usually monomorphic growth of cells exhibiting both exocrine and endocrine differentiation.

Patients with gastrointestinal MANECs appear to exhibit an improved median overall survival compared with patients with pure NECs, and this finding may be associated with the higher stage at the time of diagnosis of the latter (14). In a previous investigation of colorectal MANECs, no different patient survival was observed between NECs and MANECs (18), suggesting that certain clinical differences between NECs and MANECs may be site-associated (19). In general, MANECs are highly aggressive tumour types with a high risk for distant metastasis, and prognosis is often dismal. It is largely unclear whether the glandular or the neuroendocrine component is the major driving force of disease progression and thus crucial for metastatic cancer spread $(11,20,21)$.

In oncological practice, distant metastases are not normally assessed by histology, when the responsible primary tumour is known (22). The presented case exhibited widespread dissemination of the neuroendocrine small cell carcinoma, however, not of the adenocarcinoma component with potentially severe implications for the choice of chemotherapy. The present study determined that the time has come to reconsider the indication for testing metastatic sites in standard oncology practice. 
A
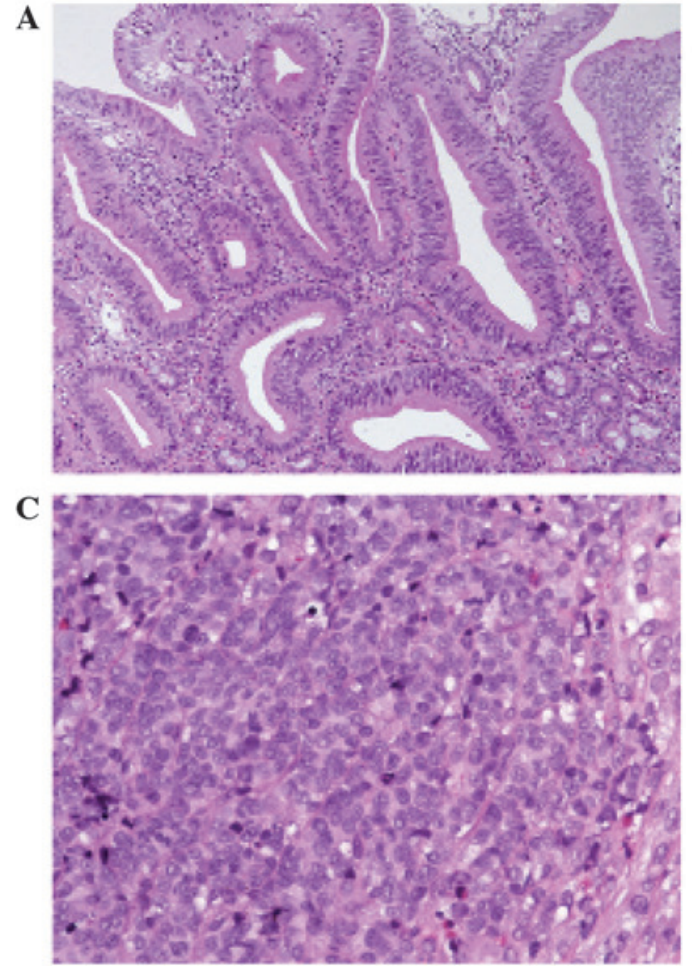

E

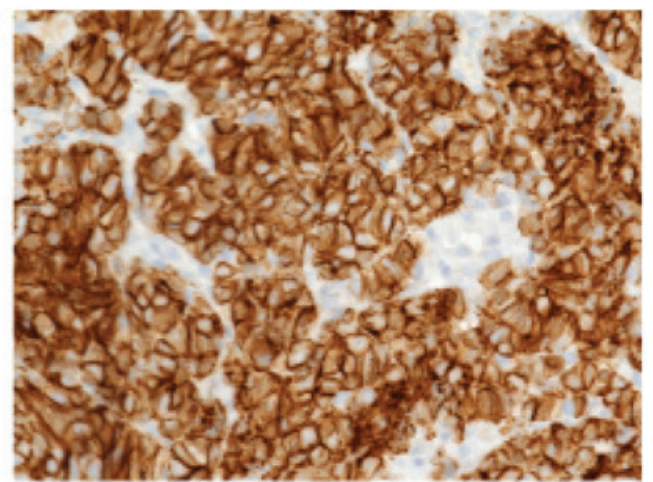

B

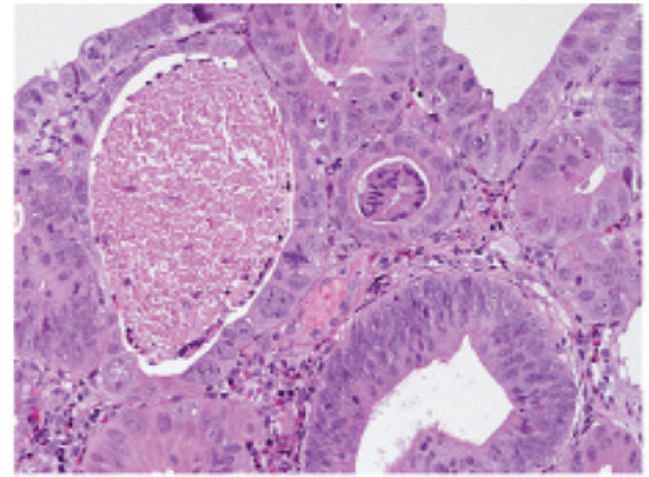

D

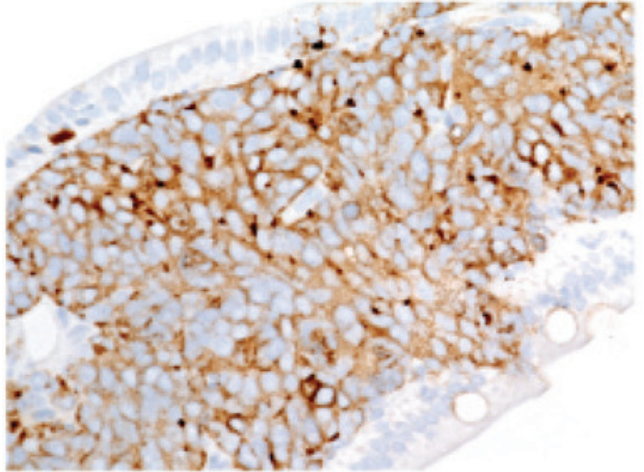

F

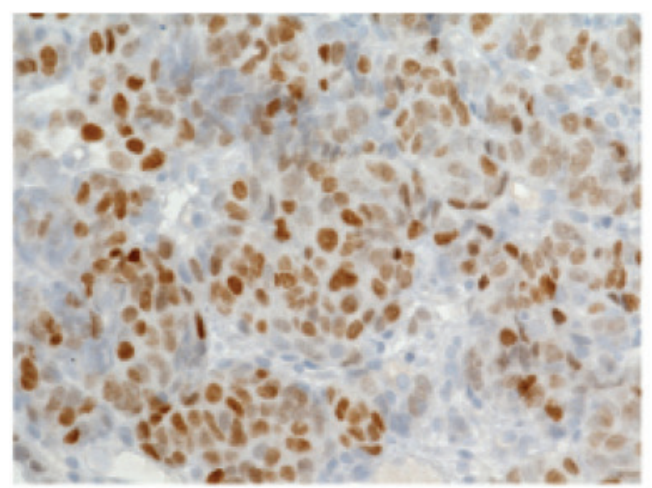

Figure 3. Histology of the primary tumour. (A) A non-invasive adenomatous precursor lesion (magnification, x100), gradually progressing into (B) an invasive adenocarcinoma of intestinal type (magnification, $\mathrm{x} 150)$. (C) Other areas of the lesion correspond to poorly differentiated neuroendocrine small cell carcinoma (magnification, x200). The neuroendocrine component was positive for (D) synaptophysin (magnification, x200) and (E) Cluster of differentiation 56/neural cell adhesion molecule (magnification, x200), while (F) caudal type homeobox-2 was expressed in both exocrine and neuroendocrine sections of the tumour (magnification, x200).
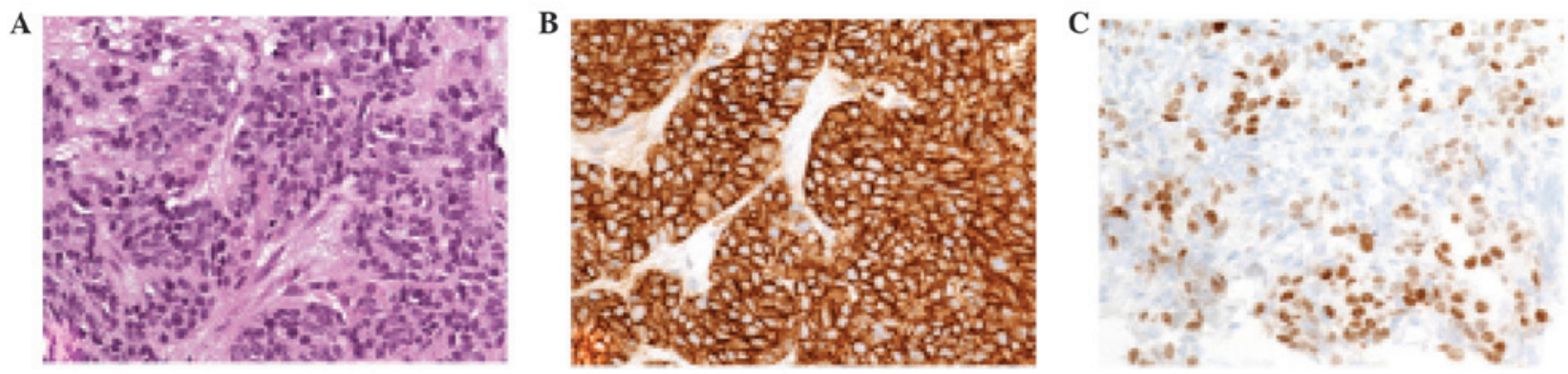

Figure 4. Immunohistochemistry of the liver biopsy. Biopsy of the liver revealed (A) metastatic neuroendocrine small cell carcinoma (magnification, x200), which is, comparable to the primary tumour. The liver biopsy was positive for (B) cluster of differentiation 56/neural cell adhesion molecule (magnification, x200) and for (C) caudal type homeobox-2 (magnification, x200), thereby proving its gastrointestinal/ampullary origin.

In conclusion, the present report presented a rare case of a MANEC originating from the ampulla of Vater. The tumour tissue from the present patient was biopsied and assessed at both primary and metastatic sites, proving discordant results. 
As exemplified by this true mixed tumour type, tumour heterogeneity evolves as the major challenge in oncology today. The assessment of metastatic sites may render valuable diagnostic information that is crucial for clinical decision-making and patient management.

\section{References}

1. Albores-Saavedra J, Hruban RH, Klimstra DS and Zamboni G: Invasive adenocarcinoma of the ampullary region. In: Bosman FT, Carneiro F, Hruban RH and Theise ND (eds). World health organization classification of tumours of the digestive system. IARC Press, Lyon pp87-pp91, 2010.

2. Kumari N, Prabha K, Singh RK, Baitha DK and Krishnani N: Intestinal and pancreatobiliary differentiation in periampullary carcinoma: The role of immunohistochemistry. Hum Pathol 44: 2213-2219, 2013.

3. Ang DC, Shia J, Tang LH, Katabi N and Klimstra DS: The utility of immunohistochemistry in subtyping adenocarcinoma of the ampulla of vater. Am J Surg Pathol 38: 1371-1379, 2014.

4. Carter JT, Grenert JP, Rubenstein L, Stewart L and Way LW: Tumors of the ampulla of vater: Histopathologic classification and predictors of survival. J Am Coll Surg 207: 210-218, 2008.

5. Kim WS, Choi DW, Choi SH, Heo JS, You DD and Lee HG: Clinical significance of pathologic subtype in curatively resected ampulla of vater cancer. J Surg Oncol 105: 266-272, 2012.

6. Robert PE, Leux C, Ouaissi M, Miguet M, Paye F, Merdrignac A, Delpero JR, Schwarz L, Carrere N, Muscari F, et al: Predictors of long-term survival following resection for ampullary carcinoma: A large retrospective French multicentric study. Pancreas 43 : 692-697, 2014

7. Nassar H, Albores-Saavedra J and Klimstra DS: High-grade neuroendocrine carcinoma of the ampulla of vater: A clinicopathologic and immunohistochemical analysis of 14 cases. Am J Surg Pathol 29: 588-594, 2005.

8. Carter JT, Grenert JP, Rubenstein L, Stewart L and Way LW: Neuroendocrine tumors of the ampulla of Vater: Biological behavior and surgical management. Arch Surg 144: 527-531, 2009.

9. Moncur JT, Lacy BE and LongneckerDS: Mixed acinar-endocrine carcinoma arising in the ampulla of Vater. Hum Pathol 33: 449-451, 2002

10. Musialik JA, Kohut MJ, Marek T, Wodołazski A and Hartleb M: Composite neuroendocrine and adenomatous carcinoma of the papilla of Vater. World J Gastroenterol 15: 4199-4200, 2009.
11. Zhang L and DeMay RM: Cytological features of mixed adenoneuroendocrine carcinoma of the ampulla: Two case reports with review of literature. Diagn Cytopathol 42: 1075-1084, 2014.

12. Huang Z, Xiao WD, Li Y, Huang S, Cai J and Ao J: Mixed adenoneuroendocrine carcinoma of the ampulla: Two case reports. World J Gastroenterol 21: 2254-2259, 2015.

13. Cordier R: Les cellules argentaffines dans les tumeurs intestinales. Arch Int Med Exp 1: 59-63, 1924

14. La Rosa S, Marando A, Sessa F and Capella C: Mixed adenoneuroendocrine carcinomas (MANECs) of the gastrointestinal tract: An update. Cancers (Basel) 4: 11-30, 2012.

15. Rindi G, Arnold R, Bosman FT, Capella C, Klimstra DS, Klöppel Komminoth P and Solcia E: Nomenclature and classification of neuroendocrine neoplasms of the digestive system. In: Bosman FT, Carneiro F, Hruban RH and Theise ND (eds). World health organization classification of tumours of the digestive system. IARC Press, Lyon pp13-pp14, 2010.

16. Khurana A, Sharma A, Gupta G and Gandhi JS: Peri-ampullary collision tumor-high grade neuroendocrine carcinoma and signet ring cell carcinoma: A case report and review of literature. Indian J Pathol Microbiol 54: 161-163, 2011.

17. Ginori A, Lo Bello G, Vassallo L and Tripodi SA: Amphicrine carcinoma of the ampullary region. Tumori 101: e70-e72, 2015.

18. La Rosa S, Marando A, Furlan D, Sahnane N and Capella C: Colorectal poorly differentiated neuroendocrine carcinomas and mixed adenoneuroendocrine carcinomas: Insights into the diagnostic immunophenotype, assessment of methylation profile and search for prognostic markers. Am J Surg Pathol 36: 601-611, 2012.

19. Klöppel G, Rindi G, Anlauf M, Perren A and Komminoth P: Site-specific biology and pathology of gastroenteropancreatic neuroendocrine tumors. Virchows Arch 451 (Suppl 1): S9-S27, 2007.

20. Harada K, Sato Y, Ikeda H, Maylee H, Igarashi S, Okamura A, Masuda S and Nakanuma Y: Clinicopathologic study of mixed adenoneuroendocrine carcinomas of hepatobiliary organs. Virchows Arch 460: 281-289, 2012.

21. Gurzu S, Kadar Z, Bara T, Bara T Jr, Tamasi A, Azamfirei L and Jung I: Mixed adenoneuroendocrine carcinoma of gastrointestinal tract: Report of two cases. World J Gastroenterol 21: 1329-1333, 2015.

22. van Krieken JH, Jung A, Kirchner T, Carneiro F, Seruca R,Bosman FT, Quirke P, Fléjou JF, Plato Hansen T, de Hertogh G, et al: KRAS mutation testing for predicting response to anti-EGFR therapy for colorectal carcinoma: Proposal for an European quality assurance program. Virchows Arch 453: 417-431, 2008. 